\title{
Health Facilities Affected by Flood Simulation to a District in Malaysia
}

\author{
Hazrin Hasim, Tahir Aris, Fadhli Yusof \\ Institute for Public Health, Ministry of Health Malaysia, Kuala Lumpur, Malaysia \\ Email: hazrin@iku.moh.gov.my
}

Received 28 September 2014; revised 29 October 2014; accepted 12 November 2014

Copyright (C) 2014 by authors and Scientific Research Publishing Inc.

This work is licensed under the Creative Commons Attribution International License (CC BY). http://creativecommons.org/licenses/by/4.0/

c) (i) Open Access

\section{Abstract}

Objective: The Ministry of Health Malaysia is developing a GIS database of health facilities in the country with the main aim to assist in the planning and development of the services, and in allocation of resources. Methodology: Apart from coordinates of the facilities, other digital information such as states and districts boundaries, main road networks and river were obtained from MacGDI, a centre responsible to manage geospatial data infrastructure in Malaysia. In assisting the Ministry of Health in its planning, one of the analyses that were conducted was a flood simulation analysis in a district in a coastal area of Peninsular Malaysia. This was done following a possibility that a tropical storm "Sonamu" would happen in that area. The objective was to identify health facilities that would be affected if a flood were to happen in the district and finally to assist the Ministry of Health in their emergency plan. Data on contour was obtain from a relevant government agency and was also mapped digitally. Results: The results were showing that with one metre depth of flood, more than half of the facilities would be affected and about two third of the facilities would be affected if the flood level rises to 2.5 metres. Conclusion: Application of GIS is very useful for the health sector in planning of facing an environmental related disaster.

\section{Keywords}

Flood Simulation, GIS, Health Facilities, Ministry of Health Malaysia

\section{Introduction}

The floods are the major disaster affecting many countries in the world. Flood is considered to be the most costly, devastating and broad extend because of the tremendous consequences [1]. Flood effects can be local, impacting a community or very large, affecting many localities or states. In Malaysia, several floods have occurred in several parts of Malaysia. They were usually either localised flash flood or basin-wide floods on major river systems. Floods from sea water as a result of heavy storms, high tide or tsunami are not a common phenomenon 
in Malaysia.

Geographical information system (GIS) has been recognized as a mean to integrate and analyse data from various sources to support disaster management especially natural disaster such as storm and flood [1] [2]. Adequate information for simulation and the capability for prediction are very important for decision making process associated with flood management. Accurate information on resources is essential to provide disaster management plan.

In the Ministry of Health Malaysia, the use of GIS in supporting services is becoming more common recently. The Ministry of Health Malaysia is in the process of developing a GIS database of health facilities in the country with the main aim to assist in the planning and development of the services, and in allocation of resources. Coordinates of health facilities were collected and mapped in the GIS database. Other digital information such as states and districts boundaries, main road networks and river were obtained from MacGDI, a centre responsible to manage geospatial data infrastructure in Malaysia.

In assisting the Ministry of Health in its planning, one of the analyses that were conducted was a flood simulation analysis in a district in a coastal area of Terengganu, a state in Peninsular Malaysia. This was done following a possibility that a tropical storm "Sonamu" would happen in that area. The objective was to identify health facilities that would be affected if a flood were to happen in the district and finally to assist the Ministry of Health in their disaster plan.

\section{Materials and Methods}

\subsection{Study Area}

The study area was a district in a coastal area of Terengganu, a state at the eastern site of Peninsular Malaysia facing the South China Sea. The size of the area is 273,500 hectare with a total population of about 150 thousand people.

\subsection{Type of Data}

There are two main types data collected for the simulation analysis. The first type of data is coordinates of the health facilities in the district. The coordinates were collected using Global Positioning System (GPS) handheld. The facilities include hospital, health clinics, rural clinics, dental clinics, "1Malaysia clinic" and district health office. The second type of data is elevation data on contour with 10 meter intervals. The data was obtained from Shuttle Radar Topographic Mission (SRTM) produced by National Aeronautics and Space Administration (NASA).

\subsection{Analysis}

In determining a correct floodplain, a terrain irregular network (TIN) was created using the contour data. The terrain irregular network was then converted to a grid format or digital elevation model (DEM) for elevation calculation. Stream network from river and lake were also converted to a grid format for the calculation.

Based on the information on elevation, flood plain boundaries were delineated using raster calculator and the calculation was done at several levels, i.e. 0.5 metre, one metre, 1.5 metre, 2 metres and 2.5 metres for the purpose of simulation. In order to determine the correct flood plain, neatlines removal was done to dissolve features based on the zone attributes.

Intersect function from geoprocessing was used to overlay flood plain boundaries with health facilities layer. Affected health facilities were determined based on the overlapped area with the flood plain. The analysis was done using Arc GIS 10.1 software.

\section{Results}

There were 38 government health facilities in the study district which comprise of 16 health clinics, 12 dental clinics, 16 rural clinics, a "1Malaysia clinic", a hospital and a district health office. The distance of the facilities from the sea were ranging from $200 \mathrm{~m}$ to about $50 \mathrm{~km}$.

Flood maps of the study area were generated with specified flood depths. The results of the simulation were showing that the number of affected facilities increases with the increase flood level. At $0.5 \mathrm{~m}$ flood level, three health facilities would be affected. At one metre depth of flood, 21 which are more than half of health facilities in the district would be affected. Most of the affected facilities at one metre flood level were within $3 \mathrm{~km}$ from 
the sea. About two third of the facilities in the district would be affected if the flood level rises to 2.5 meters. Figures 1-5 illustrates the flood simulation.

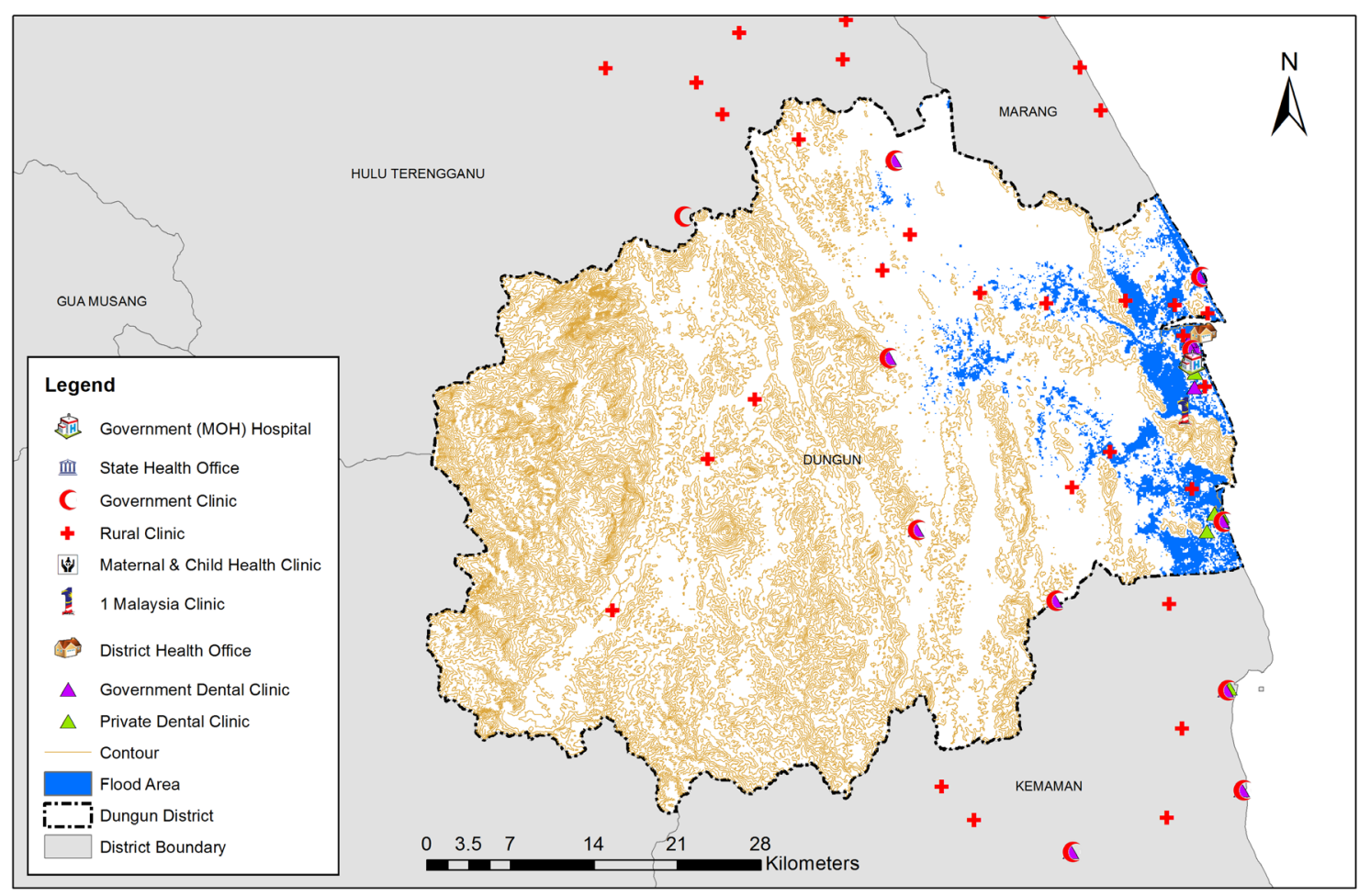

Figure 1. Flood plain boundary with 0.5 meter flood depth overlying with health facilities.

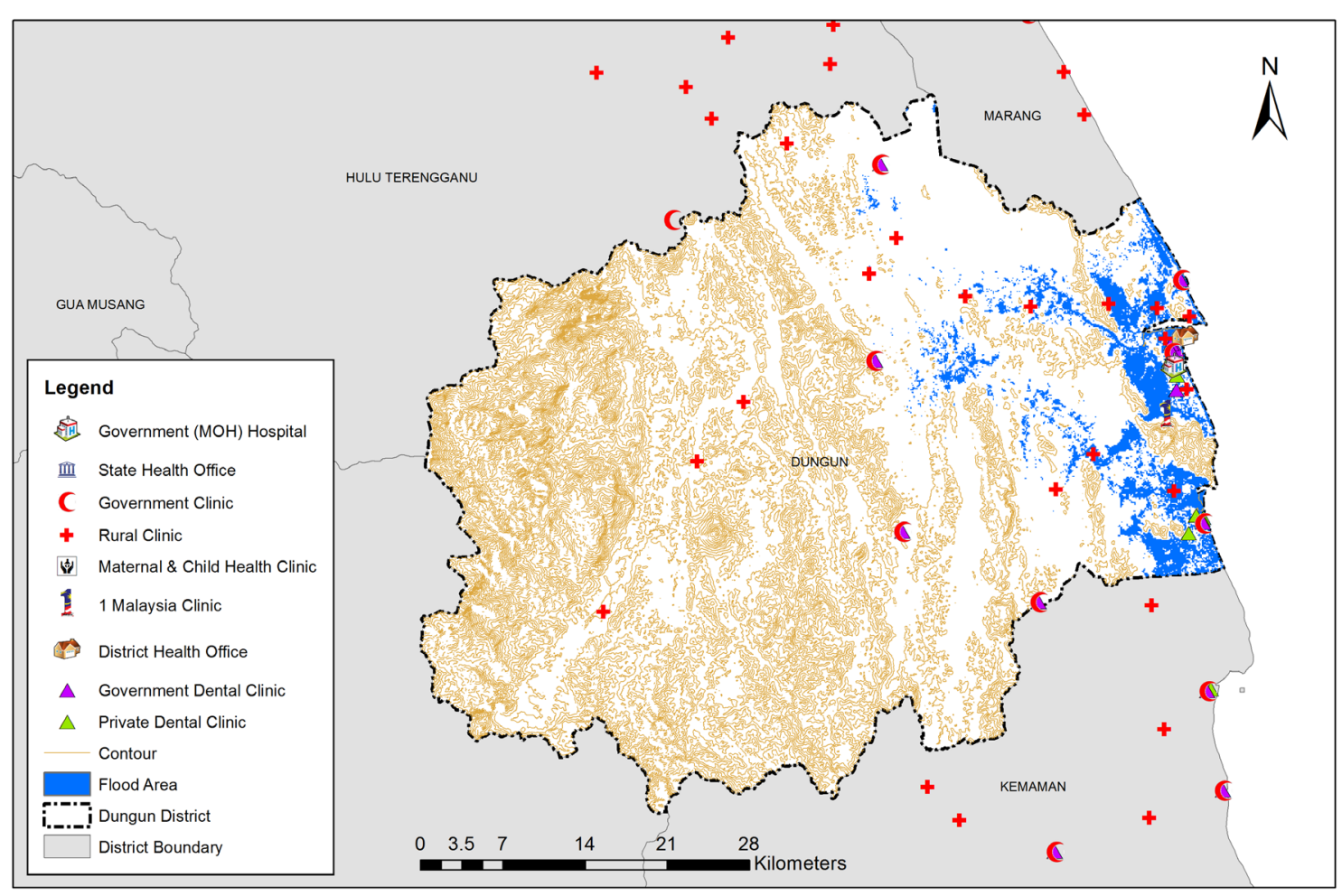

Figure 2. Flood plain boundary with 1.0 metre flood depth overlying with health facilities. 


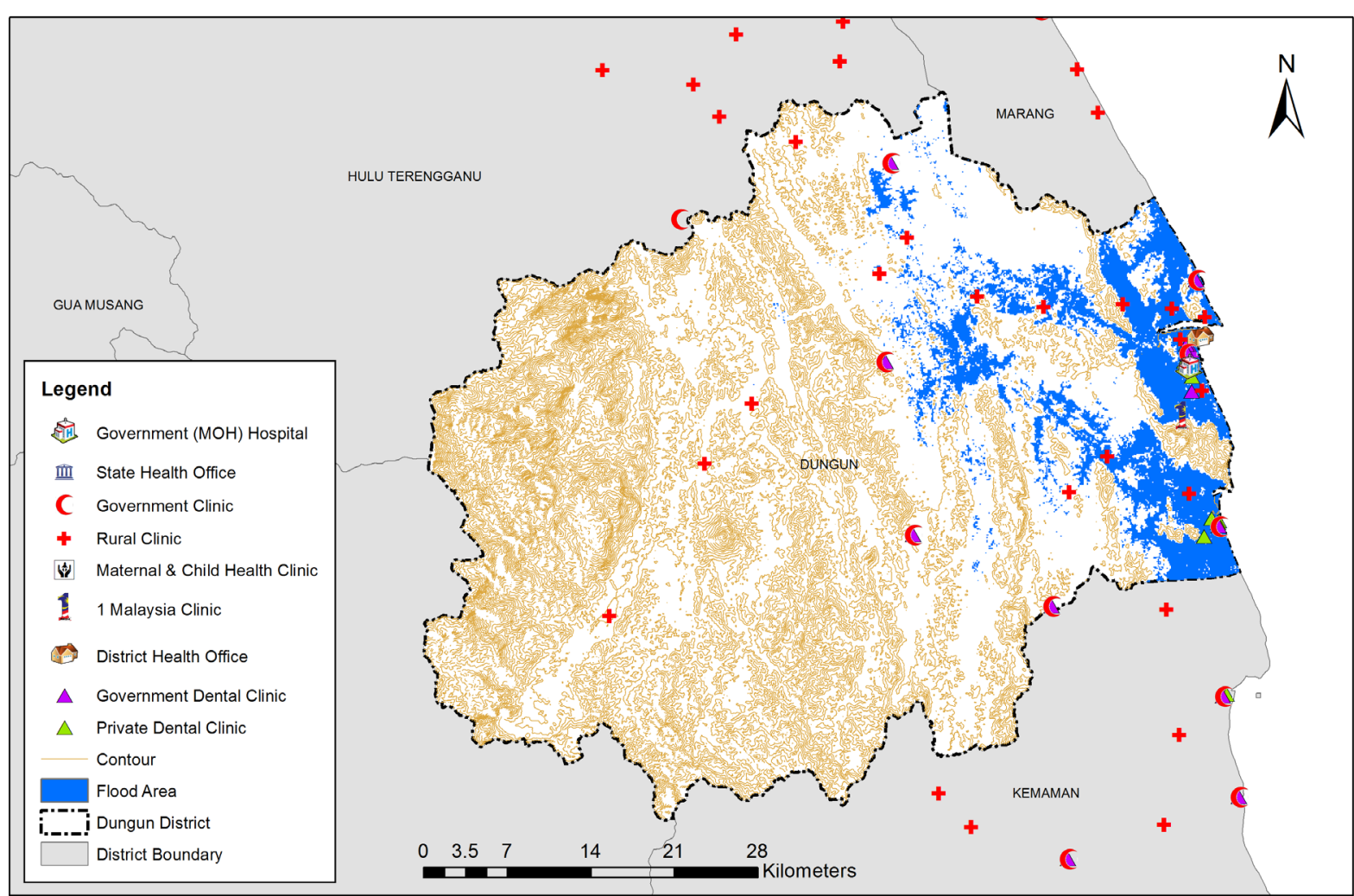

Figure 3. Flood plain boundary with 1.5 metre flood depth overlying with health facilities.

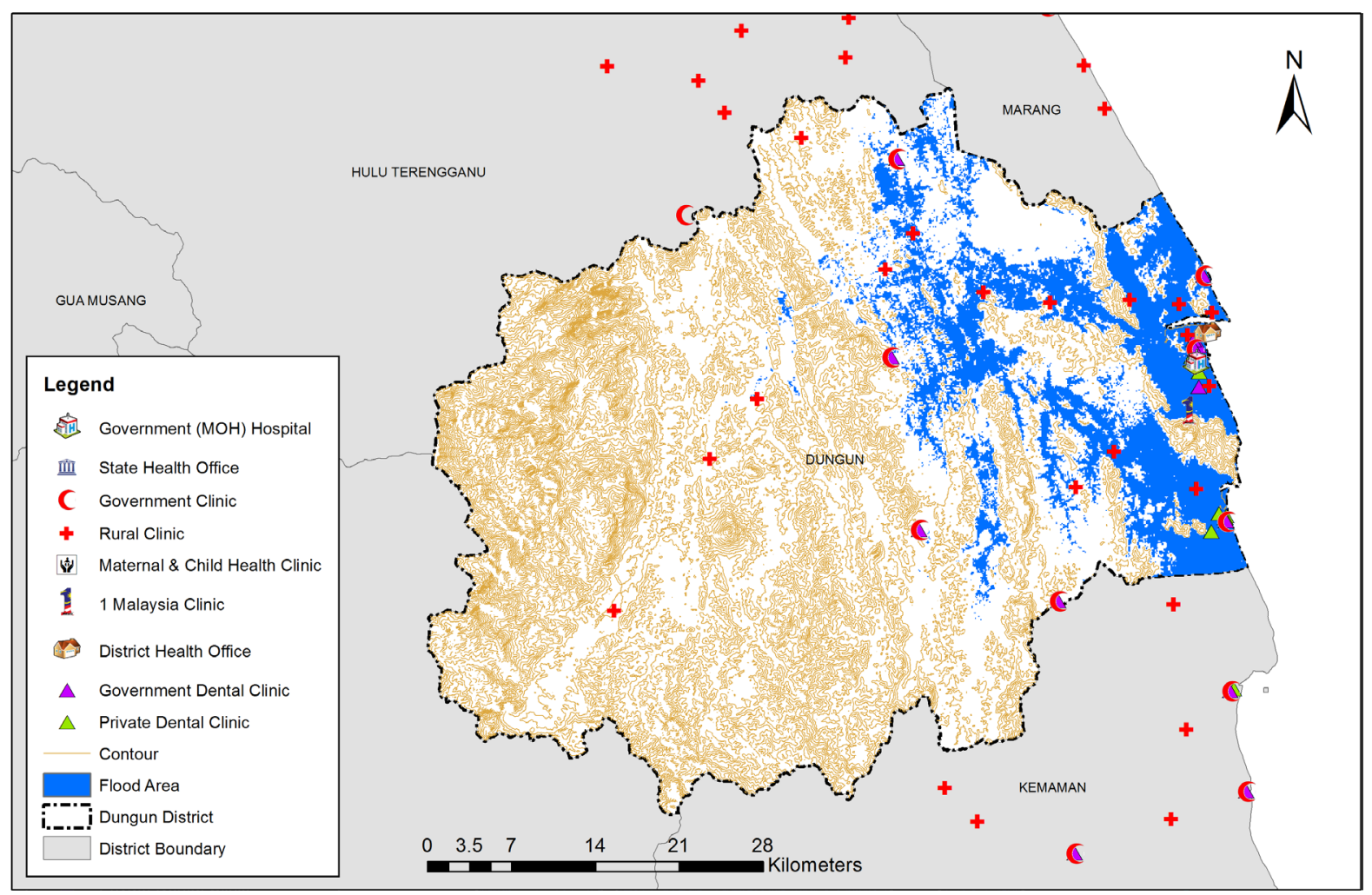

Figure 4. Flood plain boundary with 2.0 metre flood depth overlying with health facilities. 


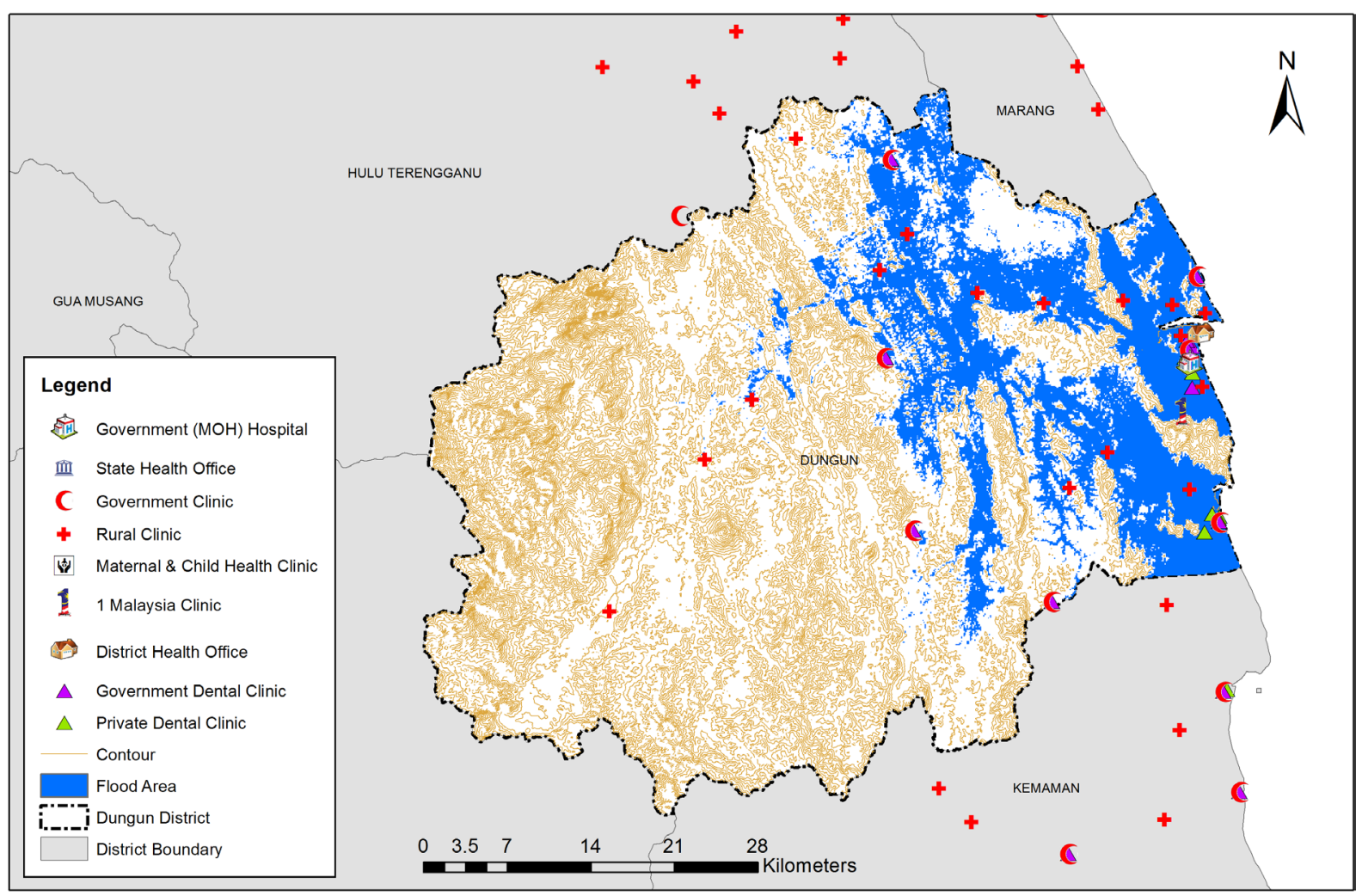

Figure 5. $2.5 \mathrm{~m}$ flood depth.

\section{Discussions}

The roles of expert in a natural disaster and flood management involve monitoring the situation, simulating a natural phenomenon as accurate as possible so as to help in coming up with better, accurate and precise forecasting models, and suitable contingency plans [3].

GIS has become a great instrument adopted in the management of flood hazard as well as risk area assessment [4]. The ability to produce a flood hazard map by delineating the predicted flood area makes it very useful in the analysis [4]. In Malaysia, a few studies using GIS applications for flood hazard mapping were conducted before [5].

Floods from sea water may be caused by heavy storm, high tide or tsunami. Although a flood as a result of a tropical storm is not a common phenomenon in Malaysia, some preparations have been made in facing the possibility of the occurrence of tropical storm "Sonamu" in the coastal area of Terengganu in Peninsular Malaysia. A GIS analysis was conducted to simulate the flood and identify the affected health facilities in the district. ArcGIS was used to simulate water level, produce flood plain and generate flood map for the specific depth.

Flood maps produced by GIS allow us to overlay with other digital information such as roads, buildings and critical facilities like health facilities. In this study, by overlaying flood map with health facilities, the affected facilities could be identified at different level of flood depths. The flood depth is believed to be the most appropriate sign indicating the risk intensity [6] [7]. This information is very useful in preparing for any contingency plan and mobilizing resources for emergency services. As the main provider in healthcare delivery in the country, the Ministry of Health Malaysia has to ensure that the services to the population would not be much affected if the storm and flood were to happen in the area.

\section{Conclusion}

The flood simulation map will help the local authorities for a quick assessment of potential impact of the flood hazard and commencement of suitable measures to reduce the impact. Application of GIS is also very useful for the health sector in simulating a natural hazard or disaster for the purpose of emergency planning. 


\section{Acknowledgements}

The authors would like to express their sincere gratitude to the Director-General of Health Malaysia for allowing to publish this manuscript. Special tribute to the Deputy Director of Health (Research and Technical Support) for the encouragement and support in the preparation and implementation of this study. Our sincere appreciation is also extended to all research team members, data collectors and processing members, and other individuals for their dedicated effort and commitment and tireless contribution in this study.

\section{References}

[1] Lawal, D.U., Matori, A.N., Hashim, A.M., Chandio, I.A., Sabri, S., Balogun, A.L. and Abba, H.A. (2011) Geographic Information System and Remote Sensing Applications in Flood Hazard Management: A Review. Research Journal of Applied Sciences, Engineering and Technology, 3, 933-947.

[2] Gharagozlou, A.R., Azmoudeh Ardalan, A.R. and Hejrani Diarjan, M. (2008) Environmental Planning for Disaster Management by Using GIS (A Case Study About Flood in Mazandaran). The International Archives of the Photogrammetry, Remote Sensing and Spatial Information Sciences, XXXVII, 323-326.

[3] Kunszewicz, Z.W., Rosbierg, D., Simonovic, S.P. and Takeuchi, K. (1993) Extreme Hydrological Events: Precipitation, Flood and Doughts. IAHS Publication, 213, 21-32.

[4] Al-Fuagara, T.A., Ghazali, A.H., et al. (2008) The Application of Hydraulic Model wih GIS for Visual Floodplain Mapping: A Case Study of Kuala Lumpur City, Malaysia. ICCBT, D(26), 273-282.

[5] Safie, M., Buang, A. and Dzurllkanian, D. (2014) GIS Analysis for Flood Hazard Mapping: Case Study; Segamat, Johor, West Malaysia. IOP Conf. Series: Earth and Environmental Science, 18, 012059.

[6] Islam, M.M. and Sadu, K. (2000) Development of Flood Hazard Maps of Bangladesh Using NOAAAVHRR Images with GIS. Hydrological Sciences Journal, 45, 337-355. http://dx.doi.org/10.1080/02626660009492334

[7] Islam, M.M. and Sadu, K. (2000) Flood Hazard Assessment in Bangladesh using NOAA-AVHRR Data with Geographical Information System. Hydrological Processes, 14, 605-620. http://dx.doi.org/10.1002/(SICI)1099-1085(20000228)14:3<605::AID-HYP957>3.0.CO;2-L 
Scientific Research Publishing (SCIRP) is one of the largest Open Access journal publishers. It is currently publishing more than 200 open access, online, peer-reviewed journals covering a wide range of academic disciplines. SCIRP serves the worldwide academic communities and contributes to the progress and application of science with its publication.

Other selected journals from SCIRP are listed as below. Submit your manuscript to us via either submit@scirp.org or Online Submission Portal.
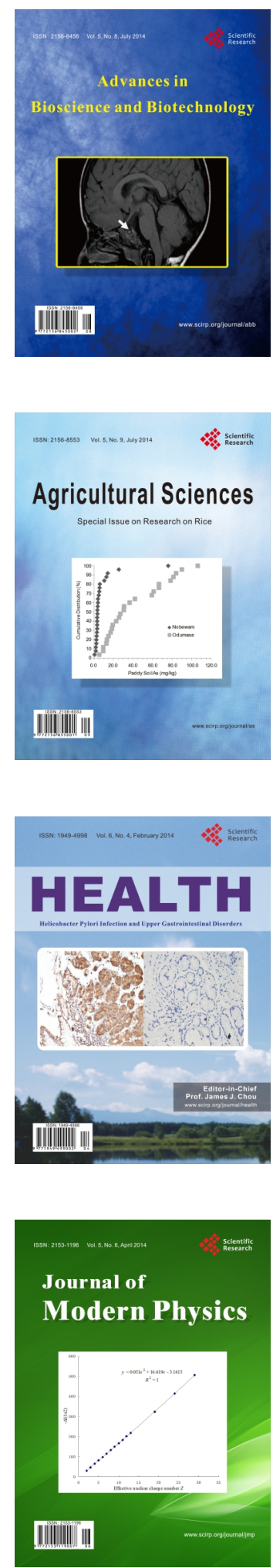
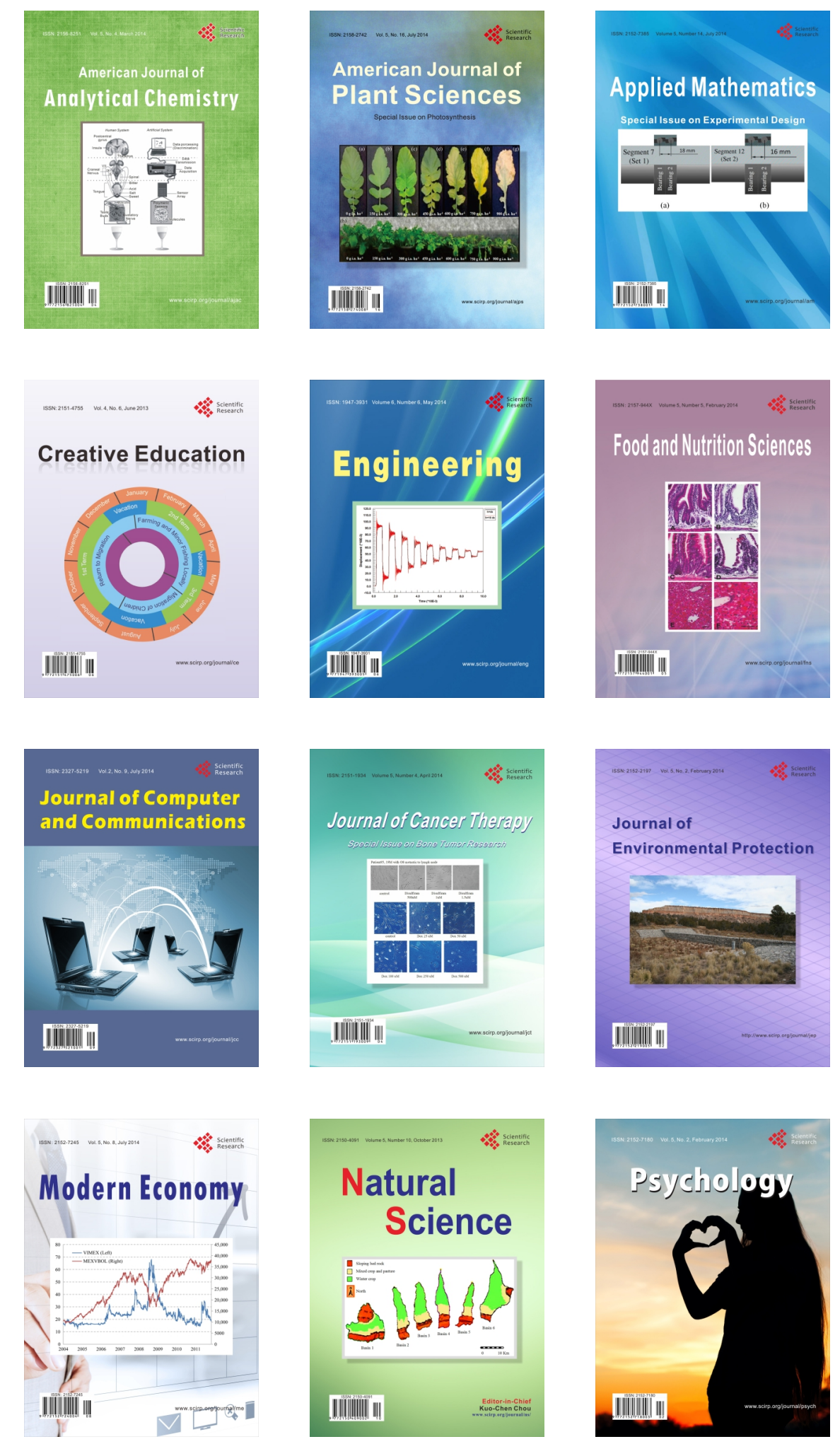